\title{
What Do Ethologists Wish to Know?
}

This issue celebrates the life and work of one of the founders of ethology and Nobel Laureate, Niko Tinbergen. Readers of Resonance will be aware that we celebrate the contributions of one scientist in every issue and in doing so, we reprint for the benefit of our young readers, one of the more important papers of the scientist being celebrated. In this issue, we wished to do the same and reprint what is perhaps Tinbergen's most important paper and certainly his most enduring legacy. However, the publishers of the original paper decided to charge us an unreasonably high amount of money which this not-for-profit educational journal cannot afford. It is a tragedy of our times that intellectual material, even when very old, is hidden inside vaults of commercial publishers and unavailable to young students who were not born when they were first published. I will, therefore, whet your appetite by providing a glimpse into the main theme of the paper in question and give a reference so that some of you may be able to find some way to read the original paper.

On the occasion of the 60th birthday of another founder of ethology and also Nobel Laureate, Konrad Lorenz, Tinbergen wrote a paper entitled, 'On the Aims and Methods of Ethology' [1]. In this paper, Tinbergen did what scientists do not do as often as they should, namely to sit back, reflect and re-examine the foundations of his discipline of study. Tinbergen evocatively called this process 'soul-searching'. Thus, Tinbergen searched his soul and asked what were the aims and methods of ethology. In doing so, Tinbergen created a map of the conceptual space of ethology and asked what ethologists really wish to know and how they go about it? Based on previous work and his own reflection, Tinbergen created an ethologist's wish list in the form of four fundamental questions namely, 1) What makes a behaviour happen (causation), 2) what is the survival value of the behaviour (function), 3) how does a behaviour develop within the lifetime of an individual organism (ontogeny), and 4) how has the behaviour changed over evolutionary time, across species (evolution)? This framework has endured and has come to be known as 'Tinbergen's Four Questions'.

I will illustrate Tinbergen's four questions using the example of birdsong. Many species of birds, especially the males (also females in some species), produce remarkably melodious songs which are not only fascinating to biologists but have long captured the imagination of writers, poets and lovers. The song of our own koel (Eudynamys scolopaceus) is a familiar example [2].

\section{(1) What Causes Birds to Sing?}

In answering this question, we study the anatomy of the sound producing organ of birds - 
the syrinx - analogous to our larynx. But the syrinx by itself cannot do much without the orchestration of several membranes and muscles that help channel air in unique ways. The membranes and muscles are controlled by elaborate neural structures and circuits in the brain. But the birds do not sing all the time. What are, therefore, the environmental and hormonal stimuli that motivate birds to sing? As you can imagine this is in itself a major field of study, aimed at understanding the mechanism of song production [3].

\section{(2) What is the Survival Value of Birdsong?}

Birds generally sing during courtship and the song helps attract mates. Where the females also sing, there is generally a duet between the male and the female. Understanding the survival value of behaviours has blossomed into a major sub-field of ethology namely, 'behavioural ecology'. There is a vast literature on the behavioural ecology of birdsong and about how females may be choosing males that sing songs of their liking, a process which Darwin referred to as 'sexual selection' [4].

\section{(3) How Does Birdsong Develop in the Lifetime of a Bird?}

This is an especially fascinating area of study because in most cases, birds are known to learn their species-specific song by a process of trial and error; they match their songs with the songs they have heard, usually their father's, songs. The brain mechanisms that permit the bird to accomplish this feat are being unravelled at a rapid pace [5].

\section{(4) How Have Birdsongs Changed Across Species?}

Such questions are usually answered by constructing phylogenetic trees of related species and noting the branches in the trees in which traits of interest (in this case, song) arise, or are lost. This question has not received adequate attention with reference to birdsong, perhaps because song is not a simple, clear trait that can be easily scored as present or absent. Nevertheless, there is an interesting study of the evolution of songs in orioles [6].

Tinbergen's four questions are sometimes divided into two groups and called proximate questions (causation and ontogeny) and ultimate questions (function and evolution) [7]. You can see how anything we want to understand about birdsong can be mapped onto one or the other of Tinbergen's four questions. Such a taxonomy of questions allows us to clarify our thoughts and make sure that we learn everything possible about any particular behaviour. Not surprisingly, this legacy of Tinbergen has endured and is being put to use not only in different branches of ethology but in other areas of biology as well. As we do with famous people, we have also begun to celebrate the birthdays of this paper! On the 50th anniversary of the publication of Tinbergen's original paper, Bateson and Laland celebrated its anniversary by revisiting Tinbergen's four questions, pointing out why they have endured and, more importantly, showing how 
modern developments in the study of ethology have made it necessary to treat Tinbergen's four questions now in a much more nuanced manner [8]. Both Tinbergen's original paper [1] and Bateson and Laland's update [8] are well worth reading.

\section{Suggested Reading}

[1] N Tinbergen, On the Aims and Methods of Ethology, Zeitschrift fur Tierpsychologie, Vol.20, pp.410-433. (This journal was renamed Ethology in 1986), 1963.

[2] A A Khan, I Z Qureshi, Vocalizations of Adult Male Asian Koels (Eudynamys scolopacea) in the Breeding Season, PLoS ONE, Vol.12, No.10, p.e0186604, https://doi.org/10.1371/journal.pone.0186604, 2017.

[3] H P Zeigler and P Marler, Eds. Neuroscience of Birdsong, Cambridge University Press, 2008.

[4] C K Catchpole and P J B Slater, Bird Song: Biological Themes and Variations, Cambridge University Press, 2008.

[5] V Gadagkar, P A Puzerey, R Chen, E Baird-Daniel, A R Farhang, J H Goldberg, Dopamine Neurons Encode Performance Error in Singing Birds,Science, Vol.354, pp.1278-1282, 2016.

[6] J Price, et al., Song and Plumage Evolution in the New World Orioles (Icterus) Show Similar Lability and Convergence in Patterns, Evolution, Vol.61, pp.850-863, 2007.

[7] R Gadagkar, Survival Strategies: Cooperation and Conflict in Animal Societies, Harvard University Press, USA and Universities Press, Hyderabad, India, 1997.

[8] P Bateson and K Laland, Tinbergen's Four Questions: An Appreciation and An Update, Trends in Ecology E Evolution, Vol.28, pp.712-718, 2013.

Raghavendra Gadagkar

Centre for Ecological Sciences and Centre for Contemporary Studies Indian Institute of Science Bangalore 560 012, India.

Email: ragh@iisc.ac.in http://ces.iisc.ac.in/hpg/ragh https://www.researchgate.net/profileRaghavendra_Gadagkar 